\title{
Richard C. Lewontin
}

\author{
Michel Veuille
}

\section{Société Française de Génétique}

\section{Président \\ A. Nicolas \\ Président d'honneur \\ F. Jacob}

\section{Vice-présidents \\ R. Berger \\ H. Pinon \\ C. Stoll}

\section{Secrétaire général}

M. Solignac

\section{Trésorier \\ P.-M. Sinet}

Prière d'adresser toute correspondance au Secrétariat général de la SFG, Michel Solignac, laboratoire de biologie et génétique évolutives, bâtiment 13, Cnrs, 91198 Gif-sur-Yvette Cedex, France.

\section{Comité de rédaction}

A. Bernheim

M. Bolotin-Fukuhara

M. Fellous

J. Génerrnont

B. Michel

R. Motta

A. Nicolas

Sommer

P. Thuriaux

D. de Vienne

Secrétaire

M.-L. Prunier
Richard Lewontin reste, à soixantesix ans, un prestigieux enfant terrible de la génétique des populations, célèbre autant pour avoir bouleversé les méthodes de recherche de sa discipline, que pour ses critiques toujours pertinentes des enjeux éthiques des recherches évolutives. Intéressé par la théorie en génétique des populations, il commença sa carrière dans les années 1950 au laboratoire de Theodosius Dobzhansky, père fondateur de la "théorie synthétique de l'évolution ". Une polémique virulente divisait alors les généticiens américains sur l'ampleur du polymorphisme génétique des populations naturelles. La vision classique maintenait que le type "sauvage" était peu variable et n'était altéré que par des mutations surtout désavantageuses. D'autres disaient que les individus différaient entre eux par un nombre considérable d'allèles. En 1966, s'associant à Hubby qui venait de mettre au point l'analyse électrophorétique du polymorphisme des enzymes, Lewontin trancha le nœud gordien en faveur des seconds et réalisa la première estimation, toujours valable, du polymorphisme des protéines. Son article, qui caracolera pendant des années au sommet du "Citation index", faisait entrer la génétique des populations de plein pied dans l'ère moléculaire. Une percée dans laquelle s'engouffreront nombre de laboratoires, et dont naîtront surtout les premières théories de l'évolution moléculaire.

Professeur à Harvard à quarante ans, mais dédaignant par engagement social une nomination à l'Académie Nationale des Sciences, Lewontin était au sommet de sa carrière lorsqu'il décida de se partager désormais entre la science et la critique de l'usage social des thèses du "déterminisme biologique». Bien qu'associé à Stephen Gould pour remettre en cause la sociobiologie, c'est en théoricien de l'étude des populations qu'il signala les limites de certains concepts de la génétique pour rejeter le "programme adaptationniste". Déjà, à la fin des années 1960, il critiquait le "racisme scientifique", alors en pleine renaissance aux Etats-Unis. Avec Marcus Feldman, il signa un article fameux (The heritability hang-up, Science 1976 ; 190 : 1163-8) sur les mesures d'héritabilité, visant notamment les tests de QI.

C'est un chercheur convaincu de l'importance des recherches en biologie moléculaire, mais aussi de leurs limites, qui signe l'article présenté ici. Initiateur en 1982, avec son élève Martin Kreitman, des premières recherches systématiques sur le polymorphisme des séquences d'ADN, Richard Lewontin consacre ses recherches à l'étude moléculaire de la sélection naturelle. Cela ne l'a pas empêché de témoigner maintes fois devant les tribunaux américains contre l'utilisation des tests moléculaires d'identification des suspects, apportant une critique de la "certitude" statistique fondée sur les calculs des coefficients de liaison et sur les populations de référence. Il est aussi l'auteur d'un réquisitoire sur quelques livres jugés par trop complaisants sur les promesses du projet "génome humain" (New York Review of Books, 28 mai 1992) 